\title{
Computation of Full-Coverage Film-Cooled Airfoil Temperatures by Two Methods and Comparison With High Heat Flux Data
}

(NASA-TH-88931) COBPCTATICA CF

FELL-COVEEAGE FILE-CCCLED AIEFCII

TELPEEATORES EY TEO METHODS ALC CCAEARISCA

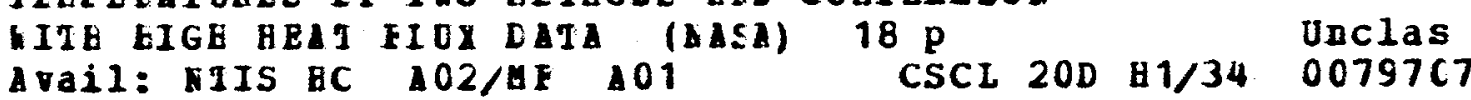

N87-23934

H.J. Gladden, F.C. Yeh, and P.J. Austin, Lewis Research Center

Cleveland, Ohio

Prepared for the

32nd International Gas Turbine Conference Exhibition sponsored by the American Society of Mechanical Engineers Anaheim, California, May 31-June 4, 1987 


\title{
COMPUTATION OF FULL-COVERAGE FILM-COOLED AIRFOIL TEMPERATURES
}

BY TWO METHODS AND COMPARISON WITH HIGH HEAT FLUX DATA

\author{
H. J. Gladden, \\ F. C. Yeh, \\ and \\ P. J. Austin Jr.
}

National Aeronautics and Space Administration

Lewis Research Center

Cleveland, Ohio 44135

ABSTRACT

Two methods were used to calculate the heat flux to full-coverage film cooled airfoils and, subsequently, the airfoil wall temperatures. The calculated wall temperatures were compared to measured temperatures obtained in the Hot Section Facility operating at real engine conditions. Gas temperatures and pressures up to $1900 \mathrm{~K}$ and $18 \mathrm{~atm}$ with a reynolds number up to 1.9 million were investigated. Heat flux was calculated by the convective heat transfer coefficient adiabatic wall method and by the superposition method which incorporates the fi.lm injection effects in the heat transfer coefficient. The results of the comparison indicate the first method can predict the experimental data reasonably well. However, superposition overpredicted the heat flux to the airfoil without a significant modification of the turbulent Prandt 1 number. The results of this research suggests that additional research is required to mode 1 the physics of fullcoverage film cooling where there is significant temperature/density differences between the gas and coolant.

\section{NOMENCLATURE}

hg heat transfer coefficient defined by Eq. (1)

$h g(\theta)$ heat transfer coefficient defined by Eq. (5)

$k$ constant

L total surface length from leading edge stagnation point

$M \quad$ mass blowing ratio, $\left(\frac{(\rho V)_{C}}{(\rho V)_{q}}\right)$

p pressure

q heat flux

Re Reynolds number s

T temperature

$V / V_{C r}$ critical velocity ratio,<smiles></smiles>

$x$

$x_{1}$ distance from applicable film cooling row

r specific heat ratio

n film cooling effectiveness

$\theta$ temperature difference ratio, Eq. (6)

$\mu \quad$ viscosity

o density

Subscripts

$\begin{array}{ll}\text { aw } & \text { adiabatic wall } \\ c & \text { coolant out } \\ g & \text { gas } \\ \text { ge } & \text { effective gas } \\ \text { meas } \quad \text { measured } \\ \text { w } \quad \text { wall outer surface } \\ 1,2,3, \text { rows of film cooling holes }\end{array}$

INTRODUCTION

Improved performance of turbojet and turbofan engines is typically accompanied by increased cycle 
pressure ratio and combustor exit gas temperature. Gas pressure levels of 25 to $30 \mathrm{~atm}$ and gas temperatures of $1600 \mathrm{~K}$ exist in some current operational engines while pressure levels up to $40 \mathrm{~atm}$ with gas temperatures of $1800 \mathrm{~K}$ are anticipated in advanced commercial engines. These continuing increases in the turbine entry gas pressure and temperature of the modern gas turbine engine and the high development cost puts a premium on an accurate initial aerothermal design of the turbine hot section hardware.

The design goals for commercial jet engines include high cycle efficiency, increased durability of the hot section components (lower maintenance costs), and lower operating costs. These goals are contradictory in that high cycle efficiency requires minimizing the cooling air requirements while increased durability requires metal temperatures and temperature aradients to be minimized. An optimum design can only be realized through an improved understanding of the flow field and the heat transfer process in the turbine gas path.

Sophisticated computer design codes are being developed which have the potential of providing the designer with significantly better initial estimates of the flow field and heat load on the hot section components. These codes are being evaluated and verified through low temperature and pressure research in cascades and tunnels. However, by design, these facilities do not model all of the processes that exist in a real engine environment, and therefore, the ability of the design codes to predict the interaction of the various parameters cannot be fully evaluated.

The Hot Section Facility at the NASA Lewis Research Center provides a "real-engine" environment with established boundary conditions and convenient access for advanced instrumentation to study the aerothermal performance of turbire hot section components. The thermal performance and, ultimately, the life of these components in a realistic application is dependent on the designer's ability to predict the local heat load distribution.

The heat flux to a stator airfoil, which has full coverage film cooling, presents a particularly challenging situation for the designer because of the complex flow field and the interaction between the hot and cold air streams. Even though film cooling has been studied for several years, there is a limited amount of realistic engine data available to verify the analytical models.

Two models have been developed to predict the heat flux to film cooled surfaces and have been discussed and compared in the literature (1). A widely used method defines the heat flux based on standard convective heat transfer coefficient and an adiabatic wall temperature. The influence of film cooling is then described in an effectiveness parameter. This approach is discussed in Ref. 2. For full-coverage film cooling, another approach is to redefine the heat transfer coefficient by incorporating the effects of coolant injection in the coefficient and then computing heat flux using the recovery temperature of the gas stream (3). In almost all verification/evalutation experiments used to define the correlation coefficients for these methods, low temperature, constant property, heated surface models are considered. In real engine applications, these deviations can have a significant effect on the designer's ability to predict the temperature and life of the structure.

The purpose of this paper is to examine these two approaches to calculating heat flux at high temperature and compare predicted wall temperatures of a turbine airfoil with measurements taken in the Hot Section Facility. These experimental data were taken at
Reynolds numbers of 1.25 and $1.90 \mathrm{million}$, gas temperatures and pressures of 1350 to $1900 \mathrm{~K}$ and 9 to $18 \mathrm{~atm}$, and coolant blowing ratios from 0.5 to 1.5 .

The results are presented as a comparison of analytical and experimental airfoil temperature distributions. Each method of calculating the heat flux to a full coverage film cooled surface is compared to the experimental data for each Reynolds number conditions.

\section{FAC ILITY}

\section{General description}

A physical Tayout of the Hot Section Facility (HSF) is shown in the perspective view (Fig. 1(a)). The HSF facility located at NASA Lewis Research Center is a unique facility having fully-automated control of the research rig through an integrated system of minicomputers and programmable controllers. The major components of this facility and how they interface together to provide a real engine environment are shown in the flow diagram (Fig. 1(b)). This facility is discussed in more detail in Refs. 4. and 5.

The main air supply system provides air at $10 \mathrm{~atm}$ to a nonvitiated preheater. The preheater modulates the air temperature between ambient and $560 \mathrm{~K}$. Through a set of routing valves, two modes of operation can be selected. Utililzing the compressor bypass system, air can be provided to the test rig at $10 \mathrm{~atm}$ and up to $560 \mathrm{~K}$. The second mode, compressor-mode, can provide air to the research rig at pressure up to $20 \mathrm{~atm}$ and a temperature up to $730 \mathrm{~K}$ when utilizing the heat of compression.

The research test rigs (Fig. 1(a)) consist of two independent test stands: a modified turbine test $r i q$ (full annular cascade riq) and a combustor test riq. The combustor test riq was used to develop and document the exit temperature profile and efficiency of the heat source for the full annular cascade. Utilizing three pairs of instrumentation rakes (temperature, pressure, and exhaust products) located at the exit of the combustor, the circumferential and radial profiles were documented providing a known input profile for the cascade vane row.

\section{Cascade configuration}

A cross-section of the Hot Section Cascade Rig is shown in Fig. 2. The major components consist of a heat source (combustor), the full annular vane row (containing full-coverage film cooled vanes), an exhaust duct line, a quench system (to lower the temperature of the exhaust gas), and the exhaust system. The vane row consists of 36 fu 11 -coverage filmcooled (FCFC) stator vanes. The 36 vanes are separated into two groups: 10 tests vanes and 26 slave vanes. The test vane and slave vane cooling air is supplied from two separate manifolds with the flow rates to each manifold independently computer controlled.

\section{FCFC vane}

The stator vane configuration used for these tests was a full-coverage $f i 1 \mathrm{~m}$ cooled design with an impingement insert to provide augmented coolant-side heat transfer. The vane row hub and tip diameters were 0.432 and $0.508 \mathrm{~m}$, respectively. Both the vane height and chord were $3.81 \mathrm{~cm}$. More detailed geometric data are qiven in Table $I$ and Ref. 6 .

A typical slave vane and test vane are shown in Fig. 3(a). The cooling air supply tube on the tip of the test vane allows cooling air to be supplied from a manifold separate from the slave vane supply. The test vane shown in Fig. $3(a)$ is in its finished form while the slave vane is shown in a partially finished form. 
A detailed airflow calibration of each test vane was performed before installation in the stator case. This information was used to select the ten test vanes with similar flow characteristics and to provide "pressure loss" coefficients for the computer code. The stator case is shown partially assembled in Fig. 3(b). The ten test vanes and some instrumentation leads are clearly shown. The cavity directly over the vane row feeds cooling air to the slave vanes while a separate manifold (downstream of the stator row) feeds cooling air to the test vanes. The top dead center positon (zero degree) is also noted in the figure. All circumferential locations arc measured in a counter clockwise (CCW) direction from this position looking downstream.

\section{Instrumentation}

Research instrumentation in the Cascade Rig consists primarily of the conventional steady-state temperature and pressure measurements. The vane airfoils carry thermocouples and pressure sensing tubes to sense the gas side metal temperatures, gas-stream static pressures, and cooling air side temperatures and pressures. Cooling air flow is controlled and measured at the venturi in each of the supply lines. Coolingair temperatures and pressures are also measured in the internal manifolds of each cooling air system.

Gas path conditions are monitored at the stator row inlet and exit. Each location has three fixed probe ports for mounting radially-actuated water-cooled probes. Radial gas-path surveys of both temperature and pressure are recorded from vane hub to tip.

A cross-sectional schematic of the vane airfoil is shown in Fig. 4 with a composite summary of instrument locations on the airfoil. The locations shown in Fig. 4 represents either metal temperature or static pressure measurements. Because each airfoil could accommodate only a limited number of instrumentation grooves, the temperature or pressure distributions reported are composed of measurements from several airfoils in the test vane sector of the annulus.

\section{EXPERIMENTAL PROCEDURE}

There were two basic modes of facility operation: 10- and 20-atm. Within each mode the research rig was operated with the combustor operating (burning) or without combustor operation (isothermal). The research objectives were to investigate the aerothermal performance of this cascade over a range of Reynolds numbers, and at a constant Reynolds number, over a range of combustor exit temperatures and pressures. The various operating modes of this facility is shown in Fig. 5 and Table II. The data reported herein are taken from cases 10 and 12 .

The gas conditions were established by setting the combustor inlet total pressure, the vane exit outer radius static pressure, and the combustor fuel/air ratio through predetermined input values stored in the operations computer. The coolant flow rate and temperature were varied systematically at fixed gas conditions either through predetermined input values to the computer or by manually inputting values to the computer.

\section{ANALYTICAL PROCEDURE}

The two methods that were used to determine heat flux to the turbine airfoil will be presented first. Then the method of calculating the airfoil wall temperatures will be discussed.
Gas-side heat flux

Method I. This method defines the heat flux using a conventional convective heat transfer coefficient and an adiabatic wall temperature.

$$
q=h_{q}\left(T_{a w}-T_{w}\right)
$$

where the adiabatic wall temperature is defined by a film effectiveness equation.

$$
n=\left(\frac{T_{\text {ge }}-T_{\text {aw }}}{T_{\text {ge }}-T_{c}}\right)
$$

where $T_{g e}$ is the effective gas temperature based on recovery of the velocity.

Although it is recognized that injection into the boundary layer will affect the heat transfer coefficient, particularly near the injection site, the value of this coefficient is typically equated to the "unblown" value. The effects of injection, geometry, etc. are incorporated in the $f i 1 \mathrm{~m}$ effectiveness term. The STAN5 (7) boundary layer code was used here in to compute the "unblown" heat transfer coefficient on the airfoil. The boundary layer was assumed to be "tripped" to a turbulent state at the first row of holes.

The film effectiveness was based on a "typical" correlation format found in the literature. One form of correlation that was developed for convex-curved surfaces is (2)

$$
\pi=k\left[\frac{x_{1}}{M_{s}}\left(\operatorname{Re}_{c} \frac{{ }_{c}}{\mu_{g}}\right)^{-0.25}\right]^{-0.8}
$$

Even though this form was originally developed for slots it is also used for rows of holes. The constant $K$ was found to be 1.50 in Ref. 8 which investigated two rows of $\mathrm{film}$ coolant injection onto a convex-curved surface with test conditions that simulated engine operation.

For a full-coverage film cooled surface, the film effectiveness related to each succeding row of holes in the downsteam direction is influenced by the film from upstream rows. The $f i l m$ effectiveness for the furthest downstream row can be calculated by the following summation (9).

$$
n_{\text {film }}=n_{1}+n_{2}\left(1-n_{1}\right)+n_{3}\left(1-n_{1}\right)\left(1-n_{2}\right)
$$

where $n_{f i l m}$ is the composite effectiveness down stream of the last row of holes.

Method 2 - The effect of film cooling is incorporated in the heat transfer coefficient for this method and the heat flux is defined by the following equation derived in Ref. 3 .

$$
q=h_{g}(\theta)\left[T_{g e}-T_{w}\right]
$$

where a dimensionless temperature parameter is defined as

$$
\theta=\left(\frac{T_{g e}-T_{c}}{T_{g e}-T_{w}}\right)
$$

Through linear superposition arguments the value of the heat transfer coefficient at any value of $\theta$ 
Eq. 3. This approach resulted in wall temperatures calculated for the suction surface which have a slope similar to the experimental temperatures but with a magnitude 100 to $200 \mathrm{~K}$ higher.

Kasagi et. al. (13) presents results that show the film effectiveness on the pressure surface to be lower than that of the suction surface for a given "blowing" ratio. Consequently, the calculations for the pressure surface were made with the constant of Eq. (3) set at 1.20. The calculated wall temperatures show good agreement with the experiment both in slope and magnitude.

The results of method 2 calculation are also shown in Fig. 9. Similar trends as method 1 are noted. The pressure surface calculations compare with the experiment reasonably well on the forward portion of the airfoil but deviate up to $100 \mathrm{k}$ higher on the aft portion. The calculations on the suction surface follow the same pattern as method 1. In order to obtain this comparison it was necessary to increase the turbulent Prandt 1 number by a factor of 3.5 above the freestream value of 0.86 as the boundary layer calculation approached the wall. A factor of 2.0 is recommended in Ref. 7 , however, a very poor comparison between analys is and experiment was obtained using 2.0. Variations in DELMR and ALAM of 2:1 from the recommended values were unable to improve the comparison. The two empirical parameters, DELMAR and ALAM, which are incorporated into the STANCOOL model to account for film injection were not sufficient to model the real engine situation.

There is no clear-cut reason why the turbulent Prandlt number should increase by this much as it approaches the wall. However, the experimental data in the literature used to determine its functional relation are generally measured with a "hot" wall and "cold" air stream which tends to destabilize the boundary layer. The data of the experiment reported herein were taken on a "cold" wall with a "hot" gas stream. This high rate of cooling of the gas stream is usually associated with a stabilizing effect on the boundary layer. This is consistant with the lower heat transfer coefficients calculated with the higher turbulent Prandt 1 number near the wall. This phenomena does not apply to the method 1 calculation since the correlation (Eq. (3)) is based on experiment with a "cold wall" and a "gas hot" stream.

There has been some arbitrariness in selecting empirical coefficients for the calculation procedures. The primary guide for the selection has been the experimental data. However, there is a basis for the selection. The point to be made is that neither calculation method has modeled the physics well enough to permit an accurate prediction of airfoil temperatures without some prior knowledge. Method 1 does model the suction surface data reasonably well especally in trend which is not surprising since the correlation is based on convex curvature data. Method 2, which is more rigorous in accounting for the physics of the problem, does as well as method 1 on the suction surface once the turbulent Prandt 1 number is modified. However, method 2 does not predict with any degree of accuracy the phenomena on the airfoil aft pressure surface.

There are many additional parameters in the STANCOOL model which could affect the calculated heat flux to the airfoil surface. Even the assumption of linearity of the energy equation could be investigated. However, the purpose of this paper is to point out the state of predicting temperatures on a ful1-coverage film-cooled airfoil in a realistic, hostile environment. In addition, topics for additional research with properly scaled temperature/density ratios have become apparent.

\section{SUMMARY OF RESULTS}

Two methods were used to calculate the heat flux to full-coverage film cooled airfoils and, subsequently, the airfoil wall temperatures. The calculated temperatures were compared to measured temperatures obtained in the High Pressure Facility. The following results were obtained.

The convective heat transfer coefficient, adiabatic wall temperature approach predicted the slope of the experimental airfoil temperatures reasonably well on the suction surface. However, the magnitude of the prediction was up to $200 \mathrm{~K}$ higher than the experimental data. The pressure surface temperature data was predicted reasonably well by decreasing the empirical coefficient of the film effectiveness correlation by 20 percent.

The modified superposition approach did as well as the first method on the suction surface for both slope and magnitude. However, there was a relatively poor comparison with the experimental data on the aft portion of the pressure surface.

The superposition method required a modification of the turbulent Prandtl number near the wall in order to obtain the relatively good comparison with the experimental data and with method 1 . The results of this research suggests that additional research is required to model the physics of full-coverage filmcooling with significant temperature/density differences between the gas and coolant as found in a gas turbine environment.

\section{REFERENCES}

1. Eckert, E.R.G., "Analys is of Film Cooling and Full-Coverage Film Cooling of Gas Turbine Blades, Journal of Engineering for Gas Turbines and Power, Vol. 106, No. 1, Jan. 1984, pp. 206-213.

2. Goldstein, R.J., "Film Cooling," Advances in Heat Transfer, Vo1. 7, J.P. Hartnett and T.F. Irvine, Jr., eds., Academic Press, New York, 1971, pp. 321-379.

3. Choe, H., Kays, W.M., and Moffat, R.J., "The Super-Position Approach to Film Cooling," ASME Paper 74-WA/HT-27, Nov. 1974.

4. Gladden, H.J., Yeh, F.C., and Fronek, D.L., "Heat Transfer Results and Operational Characteristics of the NASA-Lewis Research Center Hot Section Casecade Test Facility, "ASME Paper 85-GT-82, Mar. 1985.

5. Cochran, R.P., Norris, J.W., and Jones, R.E., "A High-Pressure, High-Temperature Combustor and Turbine-Cooling Test Facility," ASME Paper 76-WA/GT-4, Dec. 1976.

6. Moffitt, T.P., and Whitney, w.J., "Aerodynamic Effect of a Honeycomb Rotor Tip Shroud on a 50.8 Centimeter-Tip-Diameter Core Turbine," NASA TP-2112, 1983.

7. Crawford, M.E., and Kay, W.M., "STAN5 - A Program for Numerical Computation of Two-Dimensional Internal and External Boundary Layer Flow," NASA CR-2742, 1976.

8. Richard, B.E., Apoels, C., Ville, J.P., and Salemi, C., "Film Cooling on Heated Turbine Surfaces at simulated Conditions," AIAA Paper 77-947, July 1977. 
9. Colladay, R.S., "Analysis and Comparison of Wall Cooling Schemes for Advanced Gas Turbine Applications," NASA TN D-6633, 1972.

10. Crawford, M.E., Kays, W.M., and Moffat, R.J., "Full-Coverage Film Cooling on Flat Isothermal Surfaces: Data and Predictions," NASA CR-3219, 1980 .

11. Meitner, P.L., "FORTRAN Program for Calculating Coolant Flow and Metal Temperatures of a Full-Coverage-Film-Cooled Vane or Blade," NASA TP-1259, 1978.
12. Florschuetz, L.W., Metzger, D.E. and Truman, C.R., "Jet Array Impingement with Crossflow-Correlation of Streamwise Resolved Flow and Heat Transfer Distributions," NASA CR-3373, 1981.

13. Kasagi, N. Hirata M., Ikeyama, M., Makino, M., and Kurnada, M., "Effects of the Wall Curvature on the Full-Coverage Cooling Effectiveness," Presented at the Symposium on Transport Phenomena in Rotating Machinery, Honolulu, HI, Apr. 28-May 3, 1985. 
TABLE I. - STATOR VANE GEOMETRY

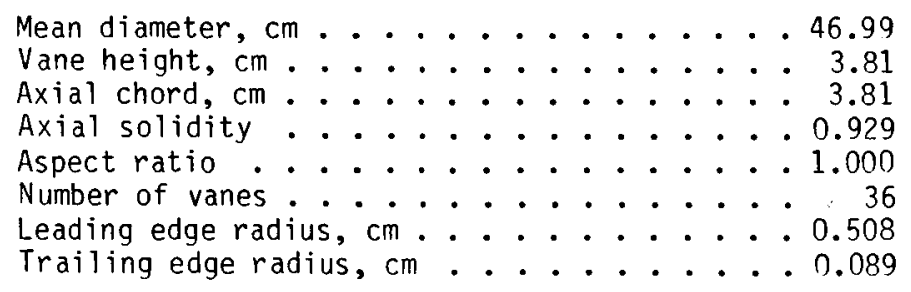

TABLE II. - HSF CASCADE RESEARCH CONDITIONS

\begin{tabular}{|c|c|c|c|c|c|c|c|}
\hline \multirow[t]{2}{*}{ Case } & \multicolumn{3}{|c|}{ Combuster exit } & \multirow{2}{*}{$\begin{array}{c}\text { Coolant } \\
\text { temperature, } \\
K\end{array}$} & \multicolumn{2}{|c|}{ Exit } & \multirow{2}{*}{$\begin{array}{c}\text { Mode of } \\
\text { operation, } \\
\text { atm }\end{array}$} \\
\hline & $\underset{K}{\text { Temperature, }}$ & $\begin{array}{c}\text { Pressure, } \\
\text { atm }\end{array}$ & $V / v_{c r}$ & & $\begin{array}{l}V / V_{c r} \\
\text { mean } \\
\text { radius }\end{array}$ & $\begin{array}{l}\text { Reynolds } \\
\text { number }\end{array}$ & \\
\hline \multicolumn{8}{|c|}{ Isothermal mode } \\
\hline $\begin{array}{l}1 \\
2 \\
3 \\
4 \\
5 \\
6\end{array}$ & $\begin{array}{l}500 \\
500 \\
500 \\
700 \\
700 \\
700\end{array}$ & $\begin{array}{l}5.1 \\
6.5 \\
8.5 \\
4.9 \\
7.4 \\
9.5\end{array}$ & 0.23 & 320 & 0.775 & $\begin{array}{l}1.25 \times 10^{6} \\
1.90 \times 10^{6} \\
2.50 \times 10^{6} \\
1.25 \times 10^{6} \\
1.90 \times 10^{6} \\
2.50 \times 10^{6}\end{array}$ & $\begin{array}{l}10 \\
10 \\
10 \\
20 \\
20 \\
20\end{array}$ \\
\hline \multicolumn{8}{|c|}{ Burning mode } \\
\hline $\begin{array}{r}7 \\
8 \\
9 \\
10 \\
11 \\
12\end{array}$ & $\begin{array}{r}1300 \\
1535 \\
945 \\
1165 \\
1500 \\
1500\end{array}$ & $\begin{array}{r}4.2 \\
5.0 \\
10.8 \\
9.0 \\
11.7 \\
17.7\end{array}$ & 0.23 & $\begin{array}{l}430 \\
500 \\
320 \\
390 \\
500 \\
500\end{array}$ & $\begin{array}{l}0.775 \\
.775 \\
.71-.83 \\
.72-.80 \\
.775 \\
.775\end{array}$ & $\begin{array}{l}0.5 \times 10^{6} \\
0.5 \times 10^{6} \\
1.90 \times 10^{6} \\
1.25 \times 10^{6} \\
1.25 \times 10^{6} \\
1.90 \times 10^{6}\end{array}$ & $\begin{array}{l}10 \\
10 \\
20 \\
\downarrow\end{array}$ \\
\hline
\end{tabular}




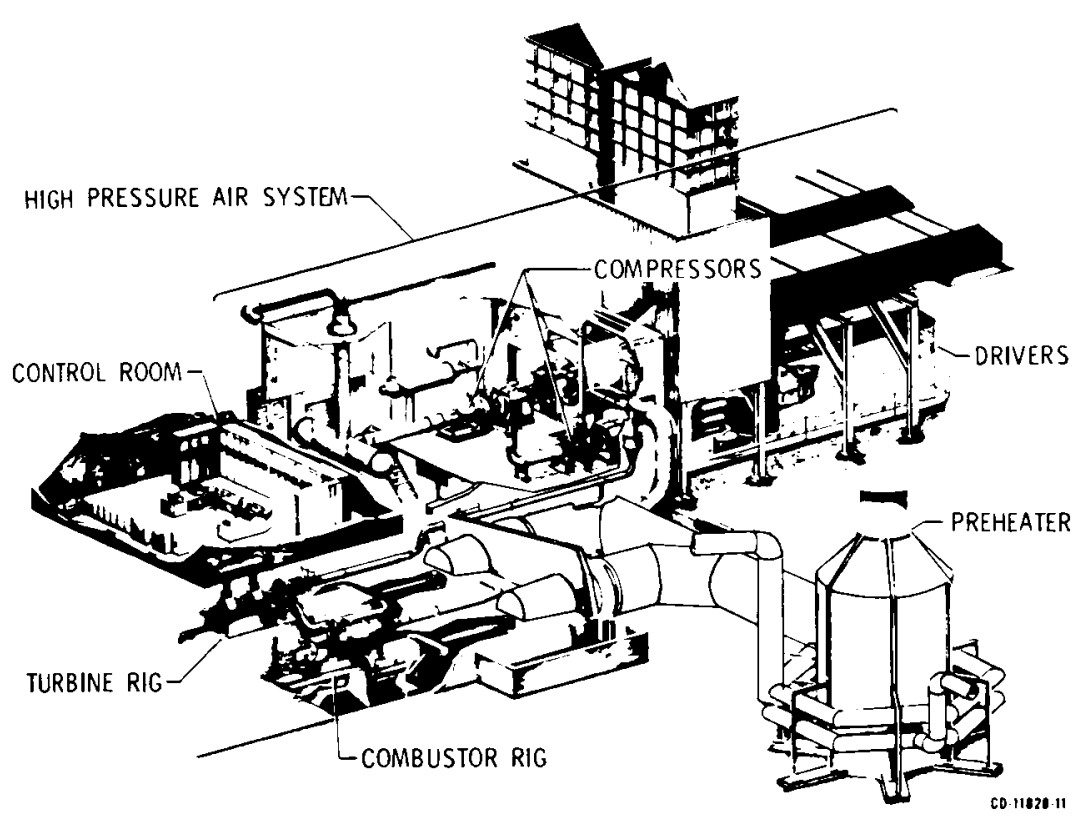

(a) Perspective view.

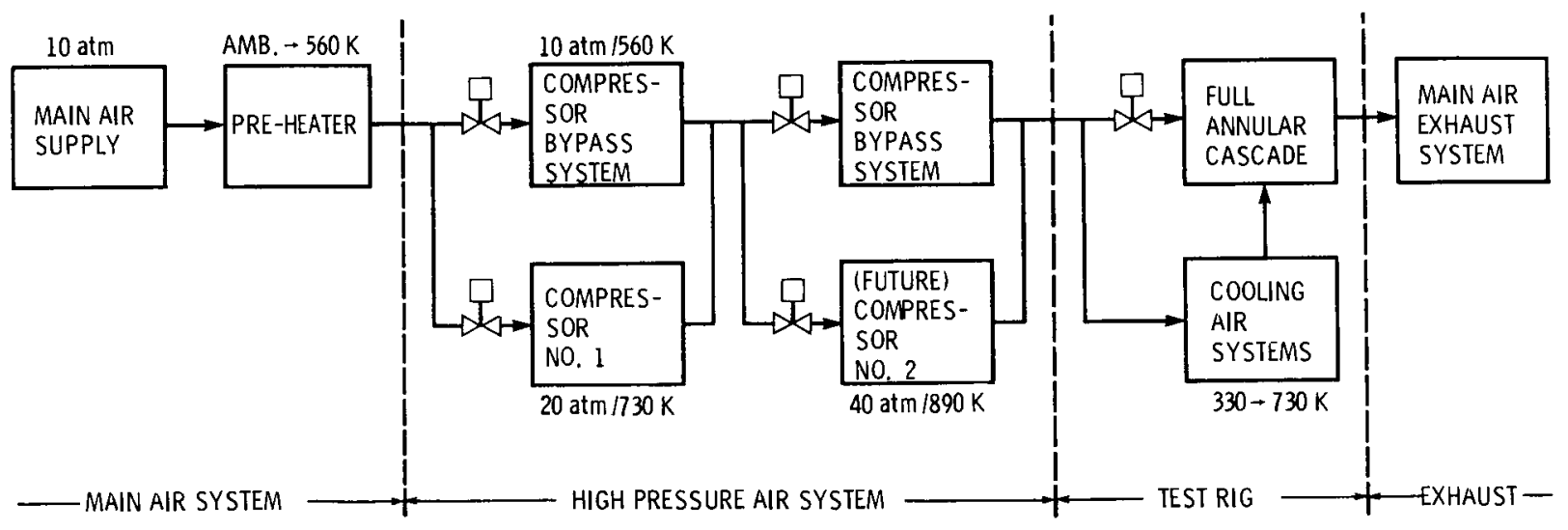
(b) HSF flow schematic.

Figure 1. - Hot section test facility. 


\section{ORIGHA PAOE IS \\ of POOR OUALTY}

STATION 6

RETRACTABLE TURBINE VANE GAS TEMPERATURE OR GAS PRESSURE SURVEY PROBE -

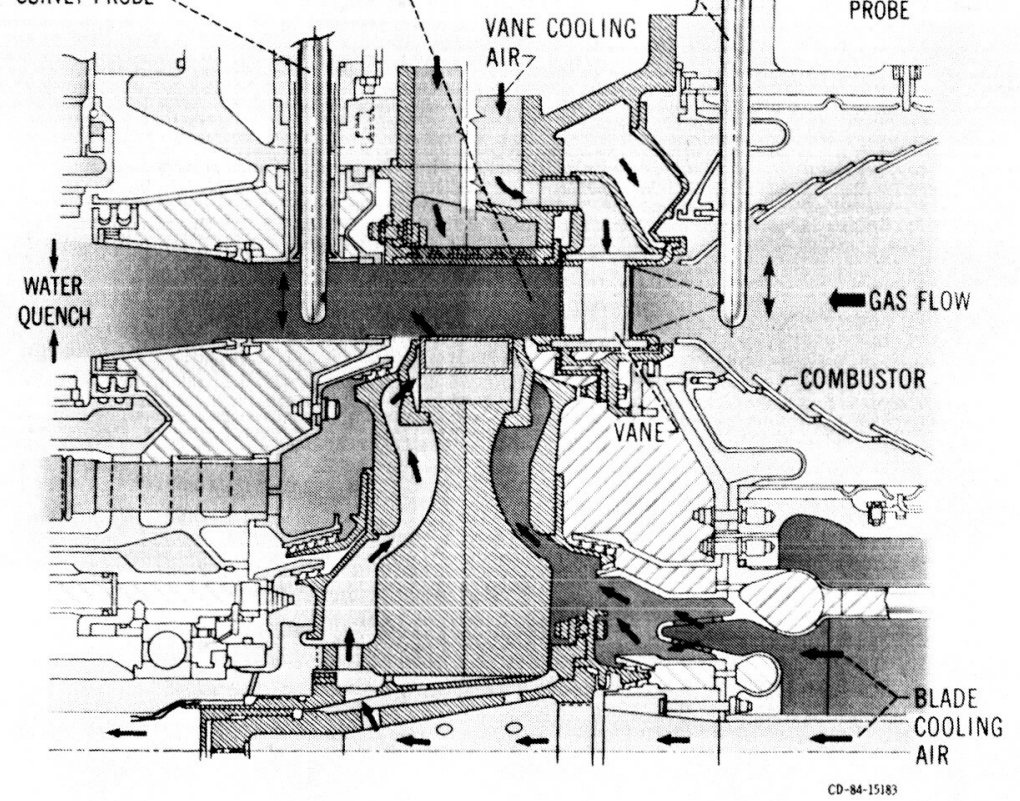

Figure 2. - Cascade schematic cross-section of the combustor and the cascade vane row. 
ORIGINAL PAGE IS

OF POOR QUALTY

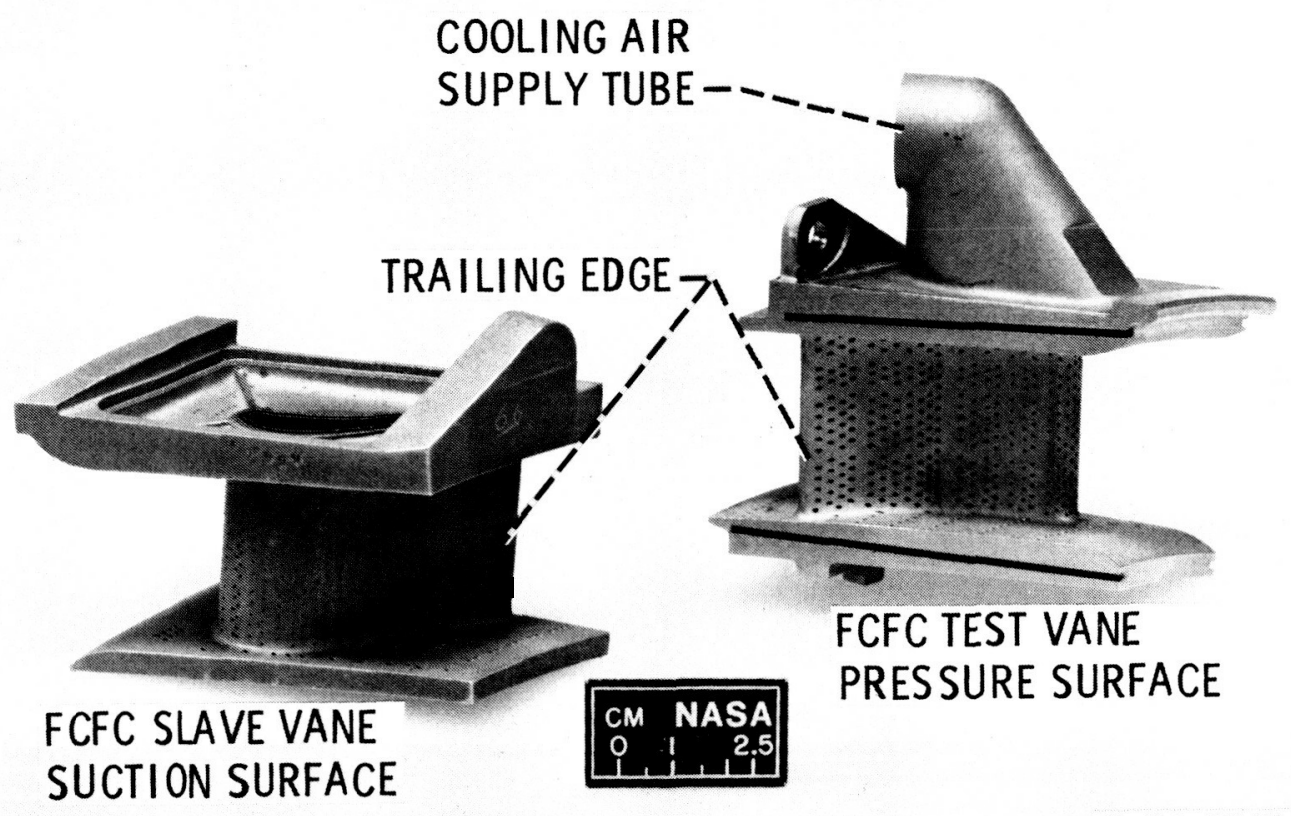

C- $84-5548$

(a) The slave vane is shown in a partially machined for $m$ while the test vane is shown in finished form.

Figure 3. - Full coverage film cooled vanes for the Hot Section Facility cascade rig. 
ORICWAL PAOE IO

OF POOP

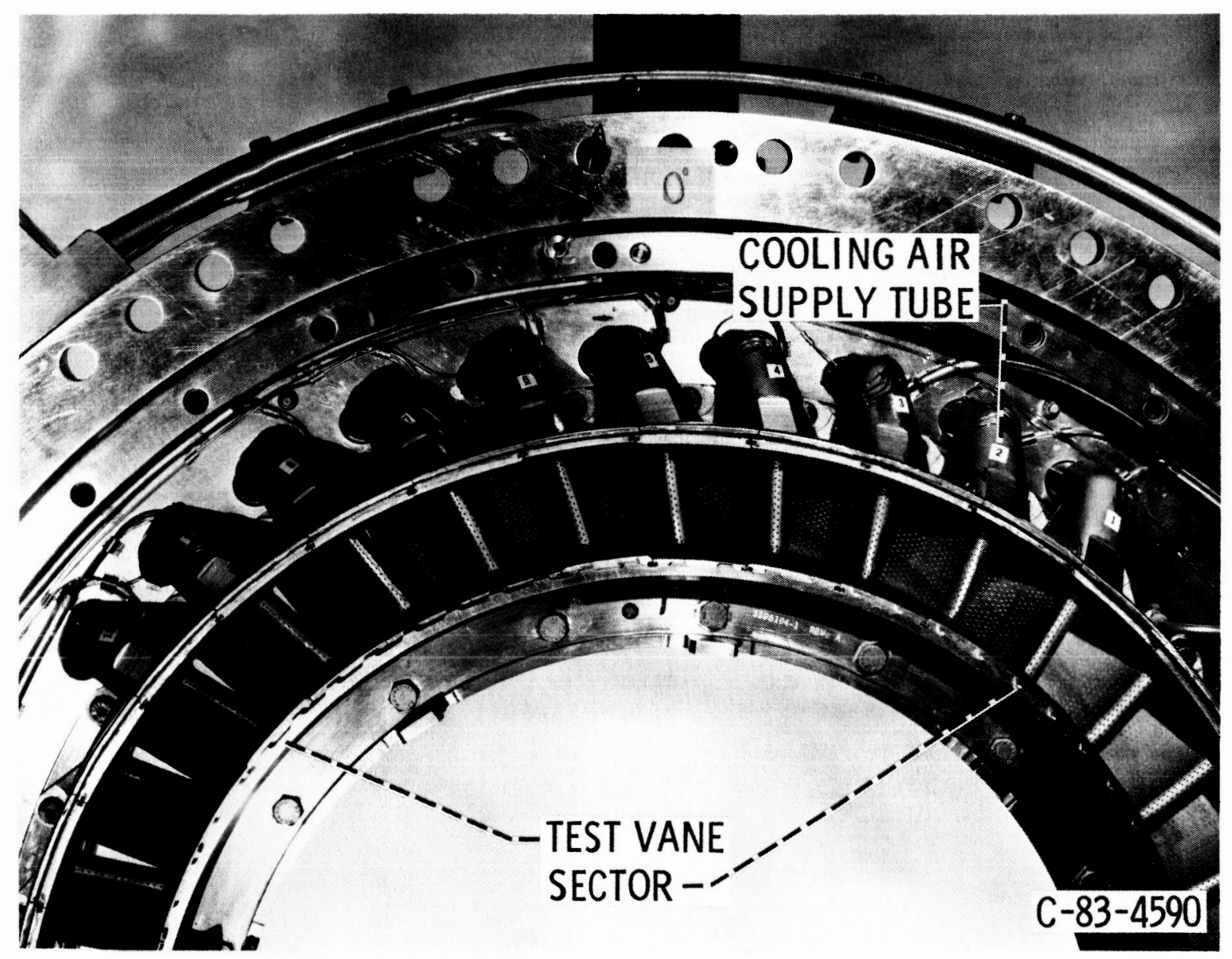

(b) Partial assembly of FCFC stator case showing test vane sector. Figure 3. - Concluded. 


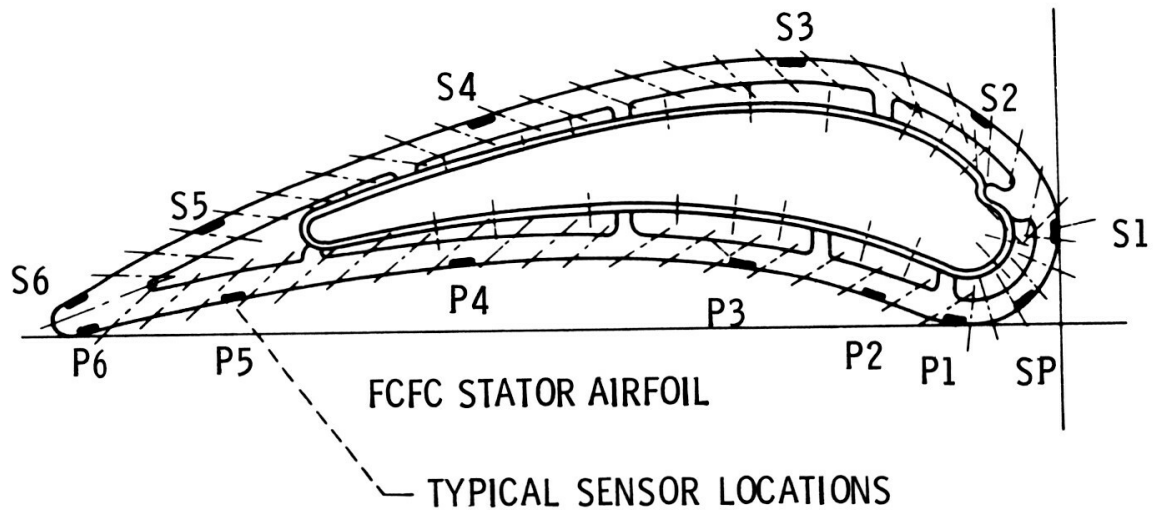

\begin{tabular}{|c|c|c|c|}
\hline \multicolumn{2}{|c|}{ SUCTION SURFACE } & \multicolumn{2}{c|}{ PRESSURE SURFACE } \\
\hline SENSOR & $x / \mathrm{L}$ & SENSOR & $x / \mathrm{L}$ \\
\hline SP & 0.0 & & \\
S1 & .067 & $\mathrm{P} 1$ & 0.083 \\
S2 & .188 & $\mathrm{P} 2$ & .174 \\
S3 & .346 & $\mathrm{P} 3$ & .314 \\
S4 & .612 & $\mathrm{P} 4$ & .587 \\
S5 & .836 & $\mathrm{P} 5$ & .826 \\
S6 & .972 & $\mathrm{P} 6$ & .973 \\
\hline
\end{tabular}

Figure 4. - Full coverage film cooled vane cross-section showing typical composite of instrumentation. 


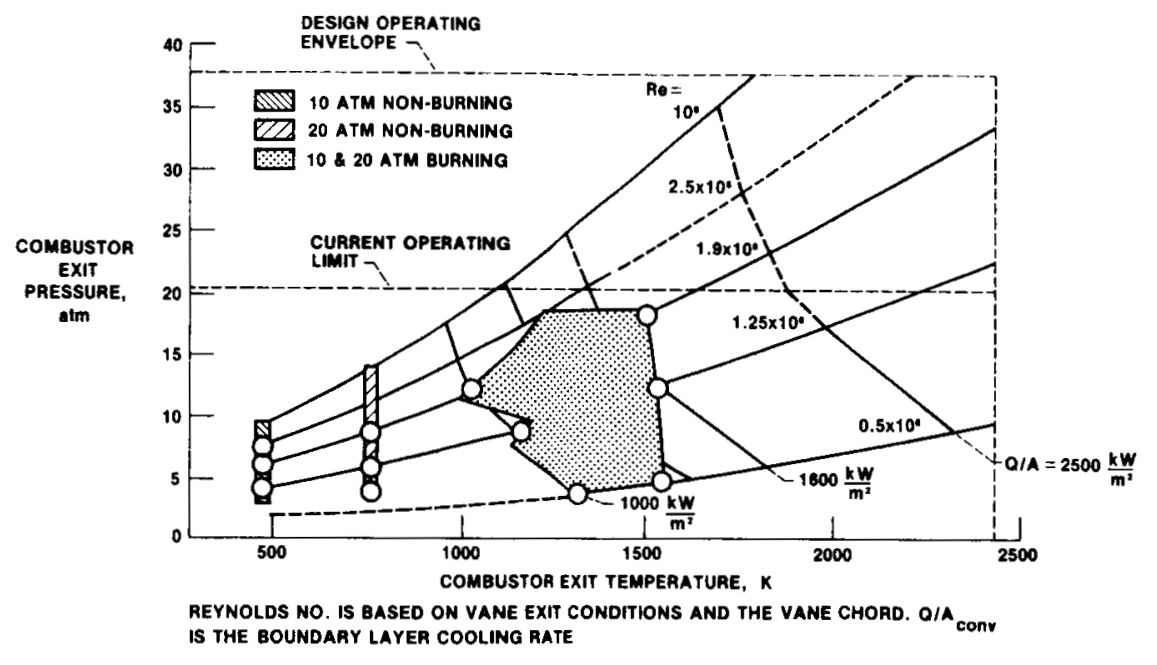

Figure 5. - Cascade rig simulation of real engine operating conditions. 


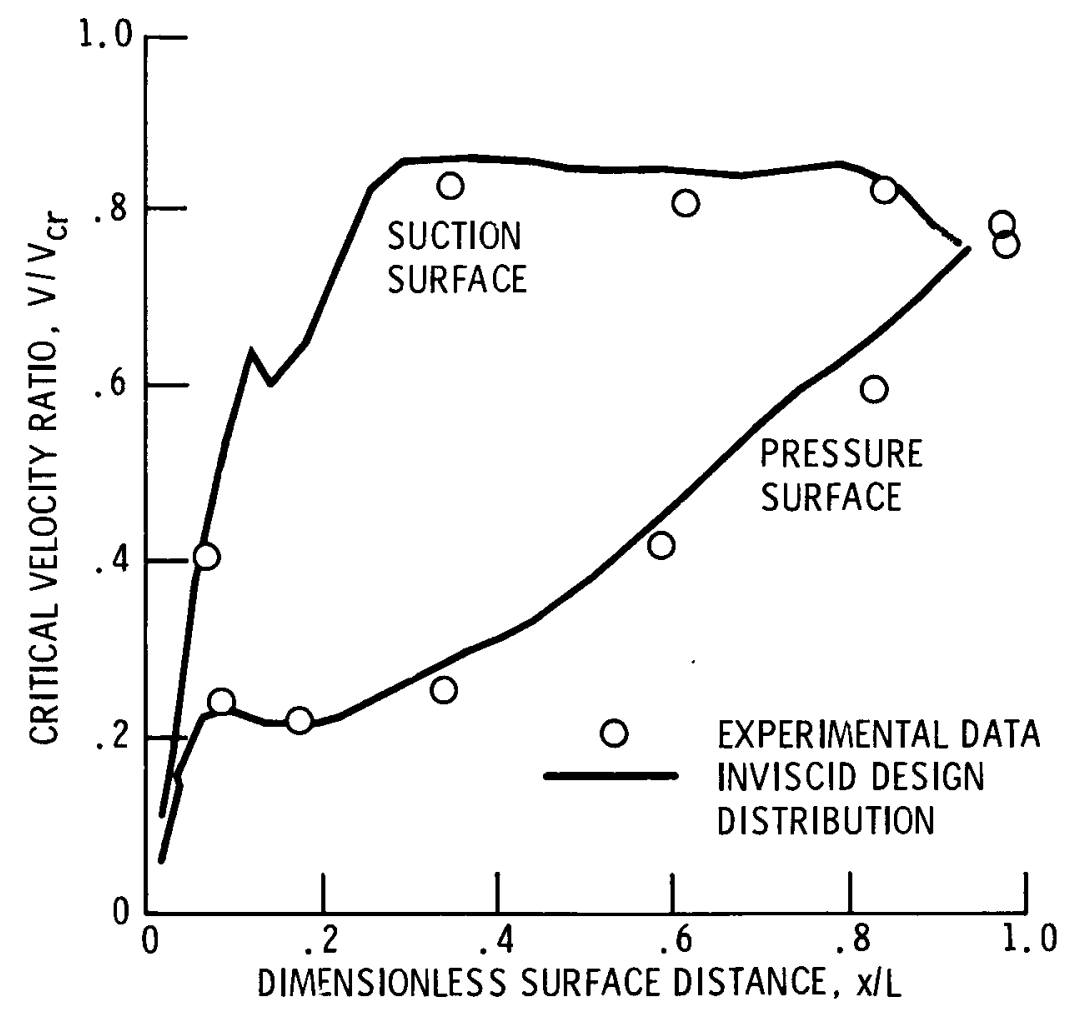

Figure 6. - Critical velocity ratio design conditions for the stator airfoil tested. 


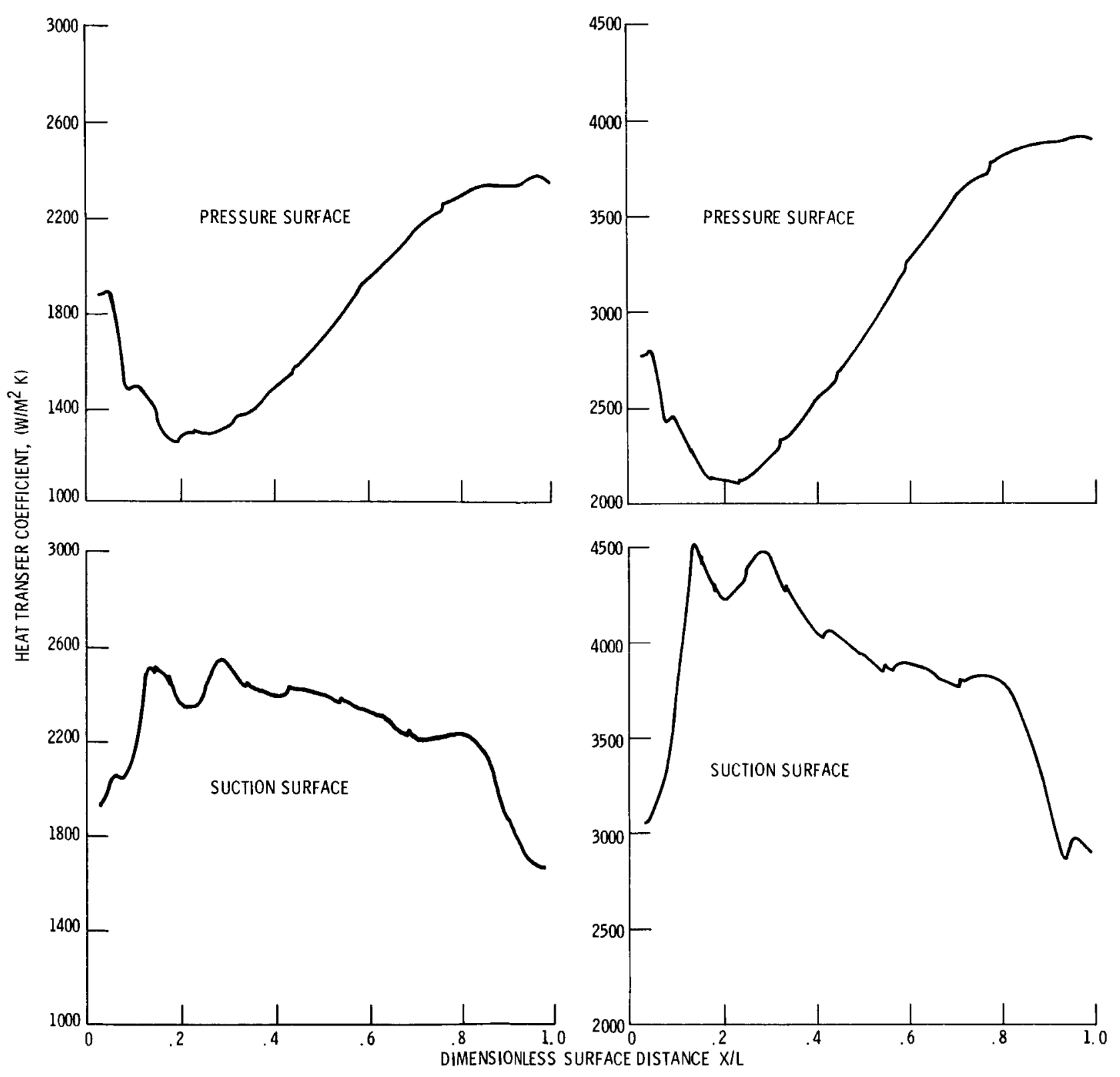

(a) Reynolds number $=1250000$.

(b) Reynolds number $=1900000$.

Figure 7. - Unblown heat transfer coefficients for method I calculated by the STAN5 boundary layer code. 


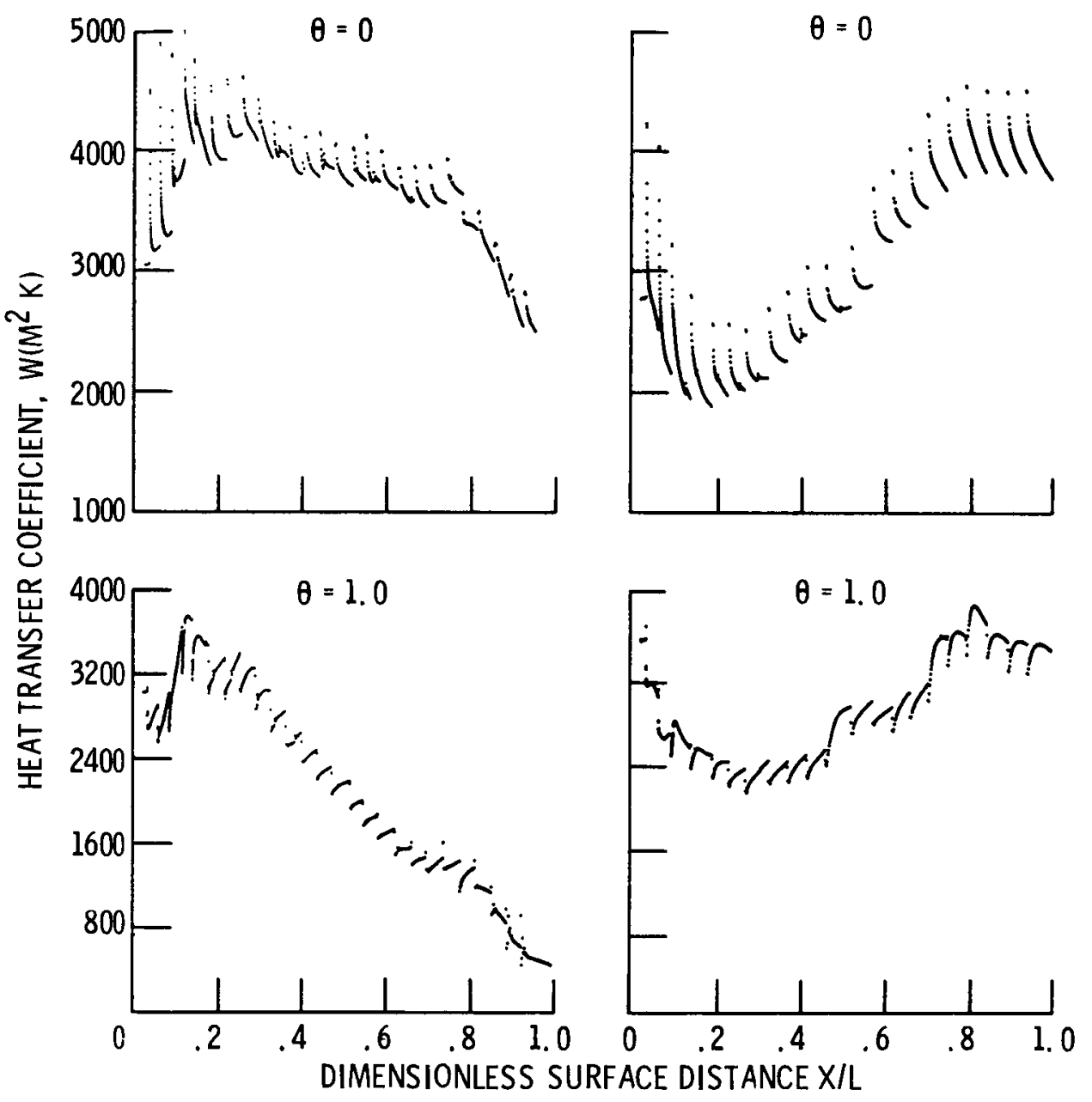

$\begin{array}{ll}\text { (a) Suction surface. } & \text { (b) Pressure surface. }\end{array}$

Figure 8. - Film-cooled heat transfer coefficients for method 2 calculated by the Stancool boundary layer code. 


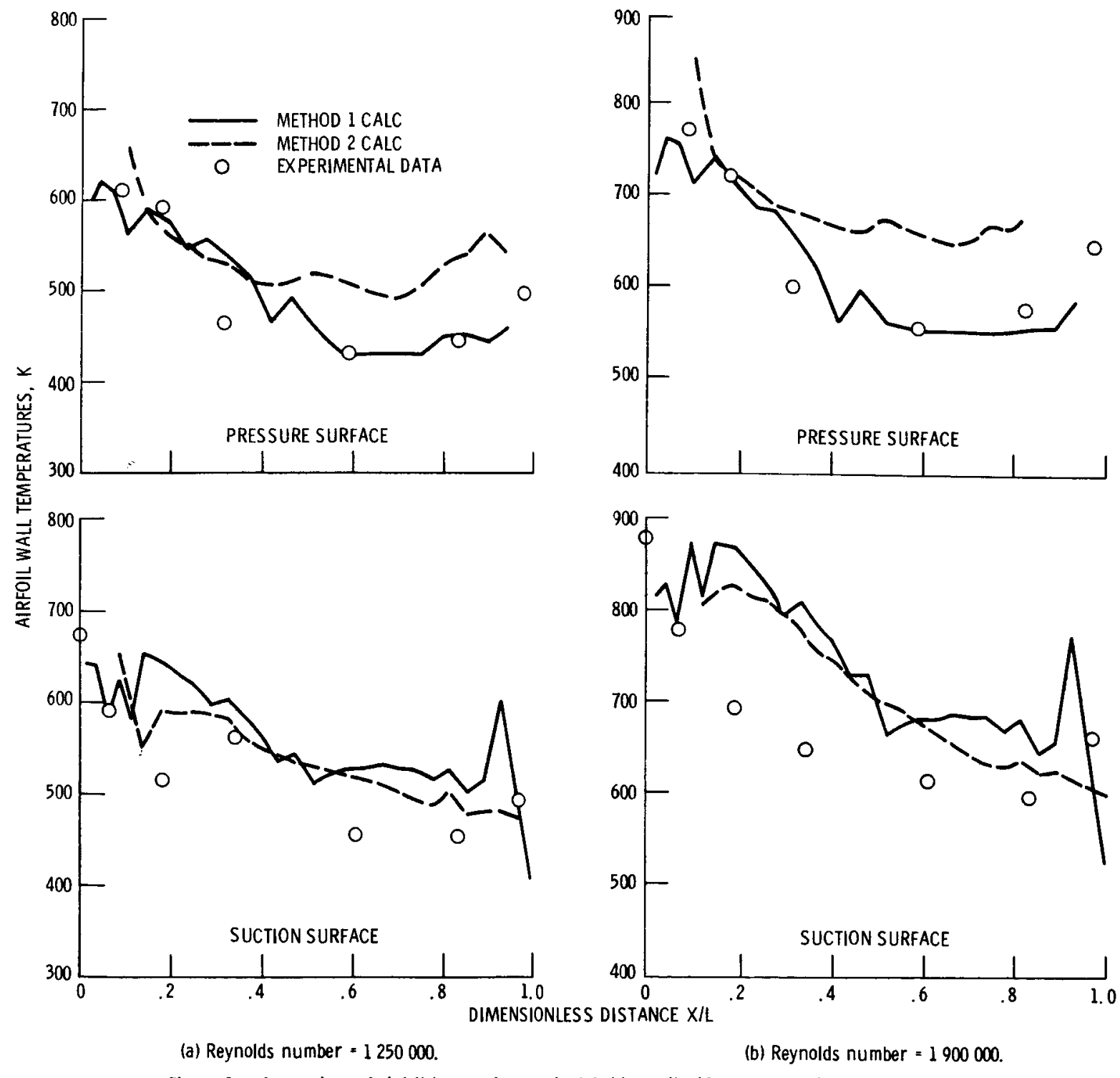

Figure 9. - Comparison of airfoil temperatures calculated by method 1 and method 2 with experimental data. 


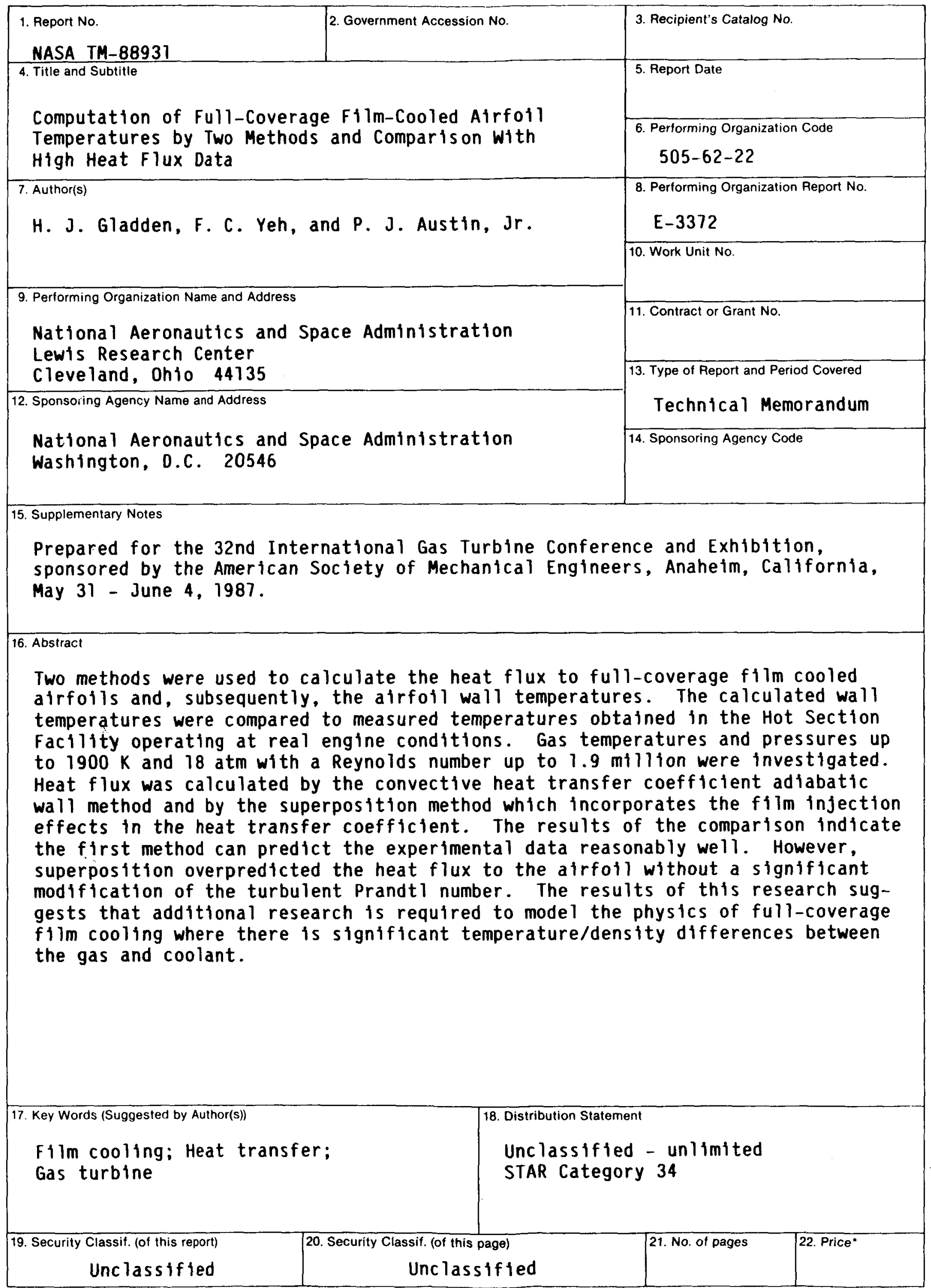

